\title{
Waste-free stores in Russia: a retrospective analysis, criticism, and analysis of the visitor's attitude
}

\author{
Ruslan Ikramov $^{* 1}$, Gleb Mityashin ${ }^{1}$, and Vladimir Bakharev ${ }^{1}$ \\ ${ }^{1}$ Peter the Great St. Petersburg Polytechnic University, 195251 Saint Petersburg, Russia
}

\begin{abstract}
The paper presents a retrospective analysis of the concept of waste-free stores in Russia. The main feature of a waste-free store is described: the need to use reusable containers for purchases. The advantages and disadvantages of waste-free stores for visitors and operators are presented in the form of a $2 \times 2$ strategic table. The impact of the pandemic on their activities is further discussed. It is recommended to change the service model from self-service to over-the-counter trading during the pandemic. Using the example of the "B12 Zero Waste" store, the possibility of creating a waste-free online store is considered. Actions that reduce the cost of creating a web representation and organizing delivery were discussed. It is emphasized that an online store is necessary for any commercial enterprise in the current conditions. It is noted that the integration of the two most relevant trends in retail (e-commerce and greening) can be a real breakthrough. The authors point out that waste-free stores simultaneously reduce the amount of discarded packaging, but significantly increase the cost of detergents and fresh water, so the wastefree concept cannot be called completely eco-friendly. The survey revealed that in Russia, most visitors have a positive attitude to the waste-free model of the store. Depending on the factors that motivate customers to make a purchase, a waste-free store can be divided into two groups: environmentally responsible and economical.
\end{abstract}

\section{Introduction}

Greening (or ecologization) is a term for minimizing the harm caused by society to the environment [1-4]. Greening has become an actual trend in retail trade due to the high social and environmental responsibility of the modern consumer and the change in the behaviour model when visiting a retail trade enterprise [5-7]. Moreover, with the growing number of people interested in environmental protection, the introduction of environmentfriendly solutions in retail trade strengthens the company's position in the competitive market and generates the loyalty of visitors [8]. Retailers must respond to this trend to attract new customers and retain those environmentally responsible visitors who are already customers of the store.

\footnotetext{
* Corresponding author: ikramov ra@spbstu.ru
} 
The paper [9] presents the directions of ecologization of retail trade. Among them, the authors distinguish:

- Commodity greening, the essence of which is greening the range of goods and increasing the number of goods in eco-friendly or recyclable packaging [10]. The paper [11] also notes the importance of using reusable shopping bags.

- Industrial greening, which consists in minimizing waste from the activities of a retail trade enterprise. The paper [9] reveals the need for the use of digital technologies, in particular Big Data technology to determine the optimal size of the supply. Several foreign articles note the importance of using eco-friendly innovations in retail as a marketing tool for the environmental component of the store's activities [12, 13].

- Greening the consumption environment, aimed at assisting the population in conscious consumption. The tools for greening the consumer environment are the acceptance of secondary raw materials from consumers and a loyalty program adapted to the environmental model.

Note that the above actions are implemented to meet the demand for eco-friendly solutions, so we can call them reactive (Fig. 1).

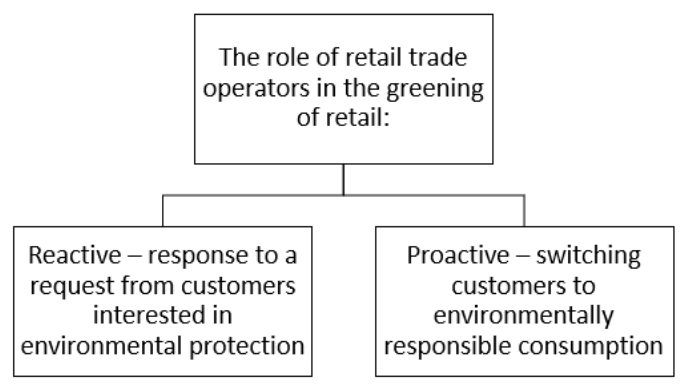

Fig. 1. The reactive and projective roles of retail trade operators.

This paper will focus on a comprehensive study of the concept of a waste-free store (one of new eco-friendly business models in retail) and a retrospective analysis of the changes that waste-free stores have undergone during the pandemic. The paper also offers a critical analysis of the waste-free concept and an analysis of the opinion of visitors.

\section{Materials and methods}

In this work, the authors used a wide range of scientific research tools. In order to provide the most complete coverage of the topic, both theoretical and empirical research methods were combined in this work. The order of the study can be presented in the form of the following list:

1. To identify the popularity of greening in our days and to study its impact on trade, the authors used general scientific methods of analysis and synthesis of Russian and foreign scientific literature. The analysis of the literature showed that only the reactive solutions of retail trade operators were studied, while the proactive ones were not.

2. To study the history of waste-free stores and their features, the authors studied online sources on a given topic. For the analysis, we used the "Zero waste" and "Day by Day" store sites. We also used the synthesis method and the method of constructing strategic tables [14].

3. Next, the compatibility of a waste-free store with e-commerce was analysed. This analysis is based on case study method (waste-free store "B12 Zero waste", which during the pandemic was able to organize online sales while preserving the features of the wastefree model). Its advantages and disadvantages were analysed. 
4. A critical analysis of the waste-free concept was conducted to determine the real impact of this concept on the reduction of waste.

5. Then we used empirical methods of scientific research. A marketing study was conducted, which allowed us to study the attitude of potential customers to the waste-free format of the store. This study also made it possible to assess the demand for waste-free stores and determine the motivation factors for visiting them. The study was conducted using the Google-forms functionality.

6. At the end of the work, we presented our vision for the further development of the waste-free concept of stores in the Russian reality.

\section{Results and discussion}

\subsection{History of the origin and analysis of the concept of waste-free stores}

The phenomenon of waste-free production originated in 1979 in the industrial sector (in 1979, the term "waste-free production " was first used). Production companies in those years thought about organizing activities with a minimum amount of waste generated, as this increases their economic efficiency (the rawer materials are used in the production process, the less new raw materials will need to be purchased). Therefore, the waste-free concept in the production sector is a natural stage of development and improvement.

In retail, the situation is somewhat different. Waste-free stores were created on the initiative of eco-activists who try to popularize the need to reduce waste [15]. The wastefree concept originated in the United States at the end of the last century as part of the anticorruption strategy. Over the next 20 years, the concept has developed, and a market has already formed in Europe and the United States, where food products are sold without packaging. Moreover, market leaders have already emerged on the European market. These companies operate under the following brands:

- "Day by Day" - in France.

- "Original Unverpackt" - in Germany.

- "Unpackaged" - in Great Britain.

Special attention should be paid to the French retailer "Day by Day", which was able to develop and popularize waste-free concept [16]. Now, "Day by Day" is not a single retail enterprise, but a retail chain with 67 stores in France and Belgium [16]. In "Day by Day" the assortment is about 750 items. "Day by Day" is positioned as a small retail trade enterprise that allows you to save money by purchasing the desired, and not imposed, quantity of goods and do not produce waste. Thus, waste-free store concept can create value for the consumer not only through an ecological approach, but also by providing the opportunity to save money. It is on the combination of tangible and intangible value that we believe the offer of such stores should be based.

In Russia, the waste-free model of stores appeared a few years ago, but it has not yet gained popularity. This model of retail is represented in Russia by single stores that operate only in big cities (Moscow, Perm, and St. Petersburg) [17]. In our opinion, this lack of popularity can be explained by the following reasons:

- The population is not fully aware of the need to minimize waste due to the large territory of the country and the availability of space for the creation of new landfills.

- Due to a relatively low level of income, people pay more attention to prices than to ecological values;

- Consumption of ecological good is in many cases less comfortable than traditional purchases. Customers are used to a certain level of comfort and do not wish to reduce it; 
Despite the reasons listed above, the no-waste model of the store still came to Russia. One of the pioneers of this market is the store "Zero waste", located a few kilometres from Moscow [17]. This is a small retail enterprise with an area of about 50 sq. m., with an assortment of about 400 products of the food and non-food groups. The waste-free operation of the store is ensured by the special formation of the assortment, which includes long-term storage products that are sold without packaging. On the shelves of stores there are bulk and liquid goods that cannot be bought by weight in a regular store. Among them are cereals, pasta, spices, dish washing products, etc. To make a purchase, the buyer must bring a reusable package in which he/she can type the necessary goods. In the case of spices, these are small bags, for cereals and detergents; reusable cans are more often used. Despite relatively high prices in "Zero waste" (since the store focuses on the quality of goods), consumers' expenses are lower in comparison with regular retail chains the buyer can determine the amount of goods he/she needs (while in regular supermarkets products are offered in a standardized packaging which is often excessive for the customers; it leads to a higher cost of purchase [17]). In "Zero waste", the buyer spends less, since he/she does not overpay for "extra" goods and does not produce garbage. The creators of "Zero waste" paid attention to the organization of work with suppliers: the key criteria for choosing suppliers for this store are not only the quality of products, but also the flexibility of packaging turnover conditions. At the moment, the store cooperates only with those suppliers who use reusable containers and take them out for reuse.

The described concept has a number of advantages, but not without disadvantages. For their analysis, the authors compiled a strategic $2 \times 2$ matrix (Table. 1), adapted to Russian conditions. As recommended in [18] for analysis of marketing innovations, the criteria used for the strategic matrix are stakeholders of the new marketing (eco-friendly) model (consumers and operators) and potential results of the implementation of this model (advantages and disadvantages).

Table 1. Advantages and disadvantages of waste-free stores.

\begin{tabular}{|c|c|c|}
\hline & Advantages & Disadvantages \\
\hline $\begin{array}{c}\text { For } \\
\text { operator }\end{array}$ & $\begin{array}{l}\text { - Unique offer on the market. } \\
\text { - A narrow target audience } \\
\text { interested in the product offered. } \\
\text { - Low cost of starting a business. } \\
\text { - High social responsibility of the } \\
\text { company. } \\
\text { - The ability to organize the } \\
\text { turnover of secondary raw materials } \\
\text { for resale. }\end{array}$ & $\begin{array}{l}\text { - Low revenue. } \\
\text { - Complexity of business expansion } \\
\text { customers. } \\
\text { - The need to work with suppliers on } \\
\text { special terms. }\end{array}$ \\
\hline $\begin{array}{c}\text { For } \\
\text { consumer }\end{array}$ & $\begin{array}{l}\text { - The ability to independently } \\
\text { determine the required quantity of } \\
\text { goods. } \\
\text { purchasing the required quantity of } \\
\text { goods. } \\
\text { required quantity of goods. } \\
\text { - Relatively higher quality and } \\
\text { eco-friendly products in the range. } \\
\text { - Introduction to the modern trend } \\
\text { of caring for the environment. }\end{array}$ & $\begin{array}{l}\text { - Time spent on the care of reusable } \\
\text { containers. } \\
\text { - The ability to buy exclusively in } \\
\text { your own packaging (there are no } \\
\text { packages and their analogues in the } \\
\text { store). } \\
\text { - Increase the time spent in the store. } \\
\text { - The need to allocate special time to } \\
\text { visit the store. } \\
\text { - Limited product range } \\
\text { - Higher price when buying an equal } \\
\text { quantity of an identical product relative } \\
\text { to a regular store. } \\
\text { - Lack of guarantees of compliance } \\
\text { with hygiene standards and storage rules. }\end{array}$ \\
\hline
\end{tabular}


A retail trade operator, opening a waste-free store in Russia, has the advantage of occupying a new niche in the market. Moreover, the store that is being opened already has a well-formed target audience, consisting primarily of environmentally responsible visitors whose values coincide with the store's concept. A rather serious plus is the company's image since the ecological basis of the store is a priori positively evaluated by modern society. It is also worth noting the low investment at the stage of opening a retail outlet (a small assortment leads to a small rental area and a small staff).

The low costs of opening a waste-free store and a rather narrow target audience lead to their main disadvantage for businessmen: small revenue and the difficulty of expanding the business. The opening of several points in the Russian conditions is possible only within one city (or its surroundings). This is since the work is carried out exclusively with local suppliers (cooperation with local supplier is a typical element of eco-friendly business strategy) [19]. This is necessary for the organization of packaging turnover and the sale of exclusively high-quality products from local suppliers. A possible option for expanding the activity of a waste-free store is not to open new outlets, but to expand the range of environmental services provided. For example, the collection of non-standard items for recycling can be organized: toothbrushes, disposable shaving machines [20]. Such goods can be accepted from visitors without compensation, and then resold for processing. Another option for expanding the business is to expand the range: in addition to reusable containers made of eco-friendly materials, you can also sell dishes.

For the visitor, the main advantages and disadvantages of non-waste stores arise from the peculiarities of their activities and are mainly associated with the use of reusable containers. Since all products are sold by weight (or by unit - like eggs), the visitor himself determines the desired quantity of goods, which means that he/she does not overpay for the excess. Moreover, the purchase of a smaller volume of each product allows you to save space at home, which is especially important in Russia, where there is a tendency to reduce the living space per person in large cities. An important advantage is the higher quality of products in comparison similar products in chain stores.

Disadvantages are also associated with the turnover of packaging, as the visitor must spend time maintaining its cleanliness and suitable condition. If the visitor for some reason forgot to bring a reusable container, it is impossible to use a disposable one. You need to overpay for reusable containers that are sold in the store. Since waste-free stores operate in the form of self-service, the buyer must independently weigh each product (first weigh the empty container and knock out a label for it, then pour the product into the container, and then weigh the container with the product again). The described procedure leads to a significant increase in the time to visit the store. Moreover, you will not be able to enter a non-waste store on your way home from work or during a walk since the visitor must have reusable containers with them. Another disadvantage is the narrowness of the range of a waste-free store, it is impossible to buy all the necessary goods for life, so visitors must go to both a waste-free store and a traditional one.

\subsection{Waste-free stores during the pandemic}

The above inconveniences have dealt an even more significant blow to the viability of waste-free stores during the pandemics. Because all goods are stored in bulk, and in stores a form of self-service is used, it is quite difficult to guarantee the sterility of the storage of goods (especially for goods that cannot be washed before use: tea or spices). For these reasons, no-waste stores need to update the model of interaction with the buyer [21]. Such solutions are the transition from self-service to over-the-counter trading and the organization of an online store. 
Over-the-counter trading is designed to ensure the sterility of the storage of goods by restricting the access of visitors to it. To do this, retail trade operator need to change the internal organization of the store, creating a space where the visitor has the opportunity to wait until the sellers collect his order. This leads to the fact that the visitor needs to know in advance what and in what quantity he/she is going to buy. The operator of the waste-free store, in turn, must hire additional workers (at least one person per shift) to ensure a higher speed of order assembly. On the one hand, this solution can help to save the traffic of a waste-free store; on the other hand, the visitor may have the feeling that the order is formed longer. When a visitor completes their own order, they are busy and do not notice how time passes. And when he stands waiting for a store employee to collect his order, he/she is inactive, which creates the illusion that the order is going to take longer. However, this is not the case, because the seller knows the location of the goods in the store better and performs the order collection faster. We can call this situation an increase in the psychological waiting time for the order.

In order to prevent the occurrence of this phenomenon, it is advisable to develop a website on which the possibility of placing a take-away order will be created [22]. That is the application of the click and collects system. When designing an online store, it is necessary to consider the features of the waste-free concept.

To study the possibility of creating a pick-up service and organizing delivery, the authors suggest using the experience of the St. Petersburg (Russia) non-waste store "B12 Zero Waste" [23].

The operator of this store decided to organize a full-fledged online store (created within the popular in Russia social network "VK") with its own delivery service, and with a pickup service. All products from this store are packed in reusable containers and sent to the courier [23]. When receiving an order, the customer has two options for accepting the order:

- Pick up the order from the courier and immediately unpack it, transferring the contents of the order to its own packaging. In this case, the customer must immediately return the container to the store's courier, who will wait outside the door while the customer sorts out the order.

- Pick up the order from the courier and return the used packaging at the next order (or bring it to the store when visiting). In this case, the store will charge a deposit of 15-30 rubbles for each unit of packaging. For the customer, this amount is not so large, but it is sufficient to cover the risks of the store in case the container is not returned. If the packaging is returned during the next order (or if it is returned directly to the store), the deposit amount will be refunded.

The attention should be paid to other features of the functioning of the online store "B12 Zero Waste". First, the range of this store has been significantly expanded by selling nonfood eco-friendly products (handkerchiefs, pens made from recycled tetrapack, products for intimate hygiene, and others), which greatly simplifies the organization of delivery. However, the store's assortment is narrow, so the number of orders is small. Therefore, the delivery details are discussed with each client individually, which is inconvenient if the number of orders increases. It should be noted the speed of delivery, which is 2-3 days (1 day is given to clarify the details and complete the order, 1-2 days are given to perform delivery), which is disastrously long for a store that sells food products. The pick-up function in this store is also available, taking into account the features described above.

It should be noted that this online store was opened with minimal costs. Since the channel of interaction with visitors is a group in a social network, its creation does not require financial resources. To create it, you only need to spend time creating a convenient navigation through the group and a detailed description of all products. After the buyer creates an order, further interaction is made with him in the same social network, which is 
convenient for both parties. Delivery is also arranged at no cost. The website contains the following information about the delivery conditions (calculations were made based on the rate of 1 dollar $=74.59$ rubles):

- Delivery to the door -4.7 dollars.

- If the distance from the metro is more than $1.5 \mathrm{~km}$, the cost of delivery is 6 dollars (if the order is from 40 dollars - 1.3 dollars).

- More than $5 \mathrm{~km}$ from the metro - the cost of delivery at taxi rates.

- Free for orders starting from 40 dollars. (you pay for the courier's work, and we make a discount of 4.7 dollars.).

- The minimum order amount is 13.4 dollars.

- Pickup from the store - free of charge (without the minimum order amount) [23].

Based on the data presented, it can be concluded that couriers work on a piecework form of payment (perhaps the store saves orders for 1-2 days, and then calls the courier to deliver them). Accordingly, the store itself does not pay for their work. Moreover, the couriers involved do not have personal vehicles, as the delivery price depends on the distance from the metro. Therefore, the store does not have to partially compensate for the cost of servicing the couriers' vehicles.

Payment for the order is made either using new digital payment tools payment links (the online store has a QR code that the customer can use to make a payment in the presence of a courier: Russia is a very advanced country from the point of view of new digital financial technologies; technological financial solutions are comfortable for customers and they are to use these innovative payment tools [31]), or it is possible to pay the courier in cash.

Thus, the store operator "B12 Zero Waste" was able to organize three key elements of the online store (web representation, payment acceptance system and delivery) with minimal costs, which allowed to strengthen the store's position in the market and reduce the negative impact of the pandemic on the business [25-27]. It should be noted that the integration of the two most popular trends in retail (e-commerce and greening) can be a real breakthrough.

The example of the "B12 Zero Waste" store shows that the organization of delivery from a waste-free store is possible, and that the concept of the store is preserved. Due to the above features, the delivery from this store cannot be called ideal, but it works and allowed the store to expand its business even during the pandemic. Operators of no-waste stores should pay attention to the model of the online store "B12 Zero Waste" and use it as a sample.

\subsection{Is a waste-free store really waste-free?}

In the first part of the study, the authors indicated that a waste-free store does not produce waste. However, the more careful analyse of the concept demonstrates that a waste-free store still produces some waste.

First, in stores, paper checks are issued, despite the fact that it is possible to send a check to the buyer by mail immediately from the cash register equipment. It should be noted that the operators of non-waste stores are actively working on this problem, sending requests asking them to allow them not to issue paper checks to customers, but permission has not yet been received.

Secondly, the turnover of reusable containers is not a completely eco-friendly solution. The visitor, after making a purchase in their own container, washes it. For washing, a detergent and a large amount of water are used, which leads to environmental pollution. A similar situation develops when organizing delivery, with the condition that the container is washed twice: first it is washed by the buyer, and after returning to the store, it is washed again. On the one hand, the concept of a waste-free store really reduces the amount of 
packaging waste, but at the same time increases the consumption of other environmental pollutants. The solution to this problem could be biodegradable packaging, but its production is expensive and currently not established in Russia.

For this reason, the waste-free model of the store cannot be called completely ecofriendly, but it is as close to it as possible.

\subsection{The attitude of visitors to waste-free stores}

To identify the opinion of visitors about the waste-free model of the store, the authors compiled a survey consisting of 14 closed questions. One of the questions had a multiplechoice answer option. The survey involved 150 respondents (109 women and 41 men), whose average age was 35 full years (respondents aged 13 to 63 years took part in the survey). The survey was conducted among residents of the Central and North-Western Federal Districts of Russia.

Since a waste-free store is an ecological innovation in retail, it is necessary to assess the respondents ' interest in taking care of the environment. To do this, respondents were asked to rate their interest in protecting the environment on a ten-point scale. In this paper, the respondent who chose the answer " 8 ", "9" or " 10 " will be called environmentally responsible (Fig. 2) [28].



Fig. 2. The level of interest in protecting the environment.

Figure 2 shows the horizontal scale of the assessment, and the vertical scale shows the number of respondents who chose a certain answer. As the results show, 126 respondents stated that they are interested in environmental protection, so they can be considered the target audience of a waste-free store. Accordingly, it is advisable to conduct further research.

After providing the introductory information, the respondents were asked to identify the reasons why the waste-free store model is attractive to them (in other words, to identify the factors that motivate them to visit a waste-free store). This question was closed, but provided for multiple choice of the answer, so the number of answers exceeds the number of respondents. The results are shown in Figure 3.

As the results show, in the Russian reality, the main motivator for visiting a waste-free store is savings. At the same time, respondents are equally interested in saving both money and space in the house, in other words, economic factors are more important for Russians than the environmental component of the store. Therefore, operators of waste-free stores should pay attention to the importance of using the economic consequences of the wastefree concept (the ability to independently determine the volume of purchases and save money without overpaying for excess) in the marketing strategy of the store. 


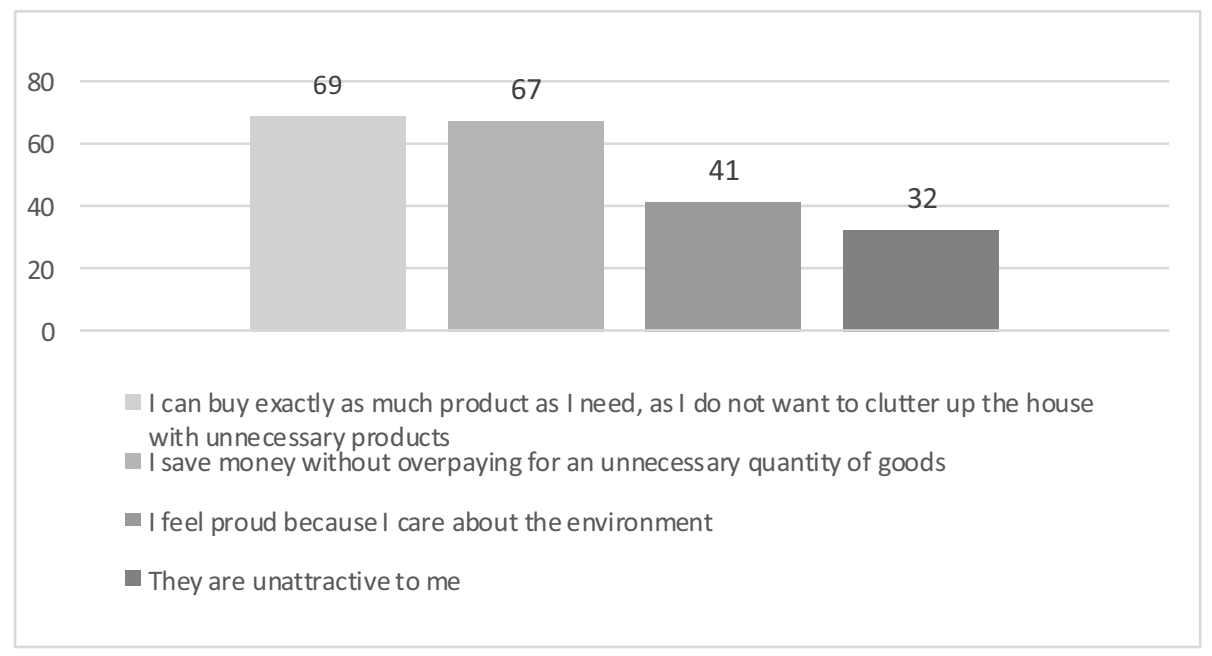

Fig. 3. Motivation to visit a waste-free store.

A key feature of a waste-free store is the need to turn around reusable containers. To identify the attitude of visitors to the use of reusable containers, the respondents were asked 5 questions presented in Table 2. The responses of the respondents were processed and summarized in Table 2.

Table 2. The results of the study.

\begin{tabular}{|l|c|c|c|c|}
\hline & \multicolumn{2}{|c|}{ Yes } & \multicolumn{2}{c|}{ No } \\
\cline { 2 - 5 } & $\begin{array}{c}\text { Number of } \\
\text { respondents }\end{array}$ & $\%$ & $\begin{array}{c}\text { Number of } \\
\text { respondents }\end{array}$ & $\%$ \\
\hline $\begin{array}{l}\text { Would you like to determine the } \\
\text { weight (volume, quantity) of the } \\
\text { product you need? }\end{array}$ & 127 & $84.67 \%$ & 23 & $15.33 \%$ \\
\hline $\begin{array}{l}\text { Are you ready to buy goods by weight } \\
\text { in your packaging? }\end{array}$ & 67 & $44.67 \%$ & 83 & $55.33 \%$ \\
\hline $\begin{array}{l}\text { Is it convenient for you to go to the } \\
\text { store with your own packaging for } \\
\text { each product? }\end{array}$ & 36 & $24 \%$ & 114 & $76 \%$ \\
\hline $\begin{array}{l}\text { Are you ready to spend time using } \\
\text { reusable containers? }\end{array}$ & 84 & $56 \%$ & 66 & $44 \%$ \\
\hline $\begin{array}{l}\text { Will you go to a waste-free store if you } \\
\text { can't buy all the products that are } \\
\text { offered in a regular store? }\end{array}$ & 67 & $44.67 \%$ & 83 & $55.33 \%$ \\
\hline
\end{tabular}

The answers to the questions presented in Table 2 confirm that a waste-free store is attractive for Russians for economic reasons $(85 \%$ of respondents would like to independently determine the volume of purchases). However, for the majority of respondents, the use of reusable containers is inconvenient. $56 \%$ of respondents are ready to keep reusable containers in good condition, but only $24 \%$ are ready to bring them to the store to make a purchase. Almost half of the respondents (45\%) are ready to visit a wastefree store, despite the narrowness of its assortment, which indicates a fairly high level of public interest in this format.

The attitude of visitors to delivery from a waste-free store was analyzed. Table 3 shows the respondents ' answers to the question of which container they would prefer to receive the delivered order in (Table 3 ). 
Table 3. Delivery from a waste-free store.

\begin{tabular}{|l|c|c|}
\hline \multicolumn{1}{|c|}{ Packaging option for delivered goods } & $\begin{array}{c}\text { Number of } \\
\text { respondents }\end{array}$ & \% \\
\hline $\begin{array}{l}\text { In the store's reusable packaging, which must be } \\
\text { returned at the next order }\end{array}$ & 20 & $13.4 \%$ \\
\hline $\begin{array}{l}\text { In the store's reusable packaging, which must be } \\
\text { returned to the courier immediately }\end{array}$ & 18 & $12 \%$ \\
\hline In a single-use package & 59 & $39.3 \%$ \\
\hline I will not use the delivery from a waste-free store & 53 & $35.3 \%$ \\
\hline
\end{tabular}

According to the results of the survey [28], 64.7\% of customers are ready to order delivery from a waste-free store, which indicates the importance of creating a new sales channel. At the same time, only $25.4 \%$ of respondents $(39.1 \%$ of respondents who agree to use delivery services) will choose an eco-friendly delivery option (reusable packaging), which corresponds to the ideology of a waste-free store and lean consumption. Such a low indicator is explained by the inconvenience of packaging turnover, which requires certain time costs. At the same time, the readiness of some respondents to use reusable containers when ordering online allows us to speak about the relevance of developing an e-commerce strategy for waste-free stores. It can be assumed that with the growing popularity of ecofriendly consumption, customers will gradually adapt to the model of using reusable containers.

\section{Summary}

Our research allows us to outline the prospects for the development of waste-free stores in Russia:

1. These stores will be opened primarily in large cities where people are more open to new trends of consumption and where the population is big enough for an eco-friendly segment of customers to exist.

2. Do not expect the emergence of a single network of waste-free stores in Russia. Most likely, they will be opened point-by-point due to the fact that it is impossible to find a single supplier in each region.

3. The range of stores needs to be expanded. Operators of non-waste stores should think about expanding the range of seasonal products, as well as expanding the non-food group.

4. In the context of the pandemic and the post-pandemic period, the creation of an online store has become mandatory for all retail trade enterprises. Accordingly, all non-waste stores that are opened need to enter the market with two sales channels: a traditional store and an online store. At the same time, a second sales channel can be created with minimal costs.

5. By reducing the amount of waste, visiting non-waste stores increases the cost of detergents and increases the consumption of fresh water, which goes against the concept of an eco-friendly store. This problem can be solved by creating a biodegradable packaging and its proper disposal.

6. In Russia, all customers of non-waste stores can be divided into two key groups, depending on the motivation to visit:

a. Environmentally responsible visitors, whose motivator is the opportunity to join the environmental protection.

b. Visitors who are thrifty about finances and free space in the house. The main motivator for them is the economic component (savings due to the purchase of the desired, rather than the imposed quantity of goods). 
7. The operator of waste-free stores in Russia must correctly differentiate these target audiences and adjust marketing activities for each of them.

\section{References}

1. V.V. Bakharev, I.V. Kapustina, G.Yu. Mityashin, Yu.V. Katrashova, Siberian Journal of Life Sciences and Agriculture, 12 (5), 79-96 (2020) DOI:10.12731/2658-6649-202012-5-79-96

2. Y.V. Vertakova, V.A. Plotnikov, IOP Conf. Ser.: Earth Environ., 392, 012078 (2019) DOI:10.1088/1755-1315/392/1/012078

3. L.A. Zazykina, A.A. Bukova, IOP Conf. Ser.: Earth Environ, 650, 012018 (2021) DOI:10.1088/1755-1315/650/1/012018

4. E.Borkova, V. Plotnikov, L. Vatlina, R. Shakhnovich, Vision 2020: Sustainable Economic Development and Application of Innovation Management, 7394-7401 (2019)

5. P. Kumar, International Journal of Retail \& Distribution Management, 42 (7), 613-625 (2014) DOI:10.1108/IJRDM-02-2013-0042

6. A. Hallorana, J. Clementc, N. Kornumc, C. Bucatariud, J. Magid, Food Policy, 49 (1), 294-301 (2014) DOI: https://doi.org/10.1016/j.foodpol.2014.09.005

7. K. Petljak, K. Zulauf, I. Štulec, S. Seuring S, R. Wagner, Supply Chain Management, 23 (1), 1-15 (2018) DOI:10.1108/SCM-04-2017-0133

8. K.V. Zakharov, A.A. Terehova, V.N. Kozlov, E.Y. Bobkova and I.A. Grigoryants, IOP Conf. Ser.: Earth Environ. Sci., 548, 052031 (2020) DOI:10.1088/1755$1315 / 548 / 5 / 052031$

9. G. Yu. Mityashin, Yu.V. Katrashov, Yu. B. Mindlin, Sovremennaya nauka: aktual'nye problemy teorii i praktiki. Seriya: Ekonomika i pravo, 1, 50-55 (2021) DOI: 10.37882/2223-2974.2021.01.17

10. T.B. Chen, L.T. Chai, Management Science and Engineering, 4 (2), 27-39 (2010)

11. S. Sumrin, S. Gupta, Y. Asaad, Y. Wang, S. Bhattacharya, P. Foroudi, Journal of business research, 122, 627-639 (2021) DOI: 10.1016/j.jbusres.2020.08.001

12. M. De Silva, P. Wang, A. Kuah, Journal of Business Research, 122, 712-724 (2021) https://doi.org/10.1016/j.jbusres.2020.01.016

13. D.C. Dabija, C.M. Pop, Environmental Engineering and Management Journal, 12(2), 393-400 (2013)

14. T. R Gareev, V.V. Belsky, Innovation, 2 (196), 50-57 (2015)

15. E.I. Balalova, O.V. Baskakova, M.S. Machabeli, T.V. Rudakova, A.V. Tkach, Frontier Information Technology and Systems Research in Cooperative Economics, 767-776 (2021)

16. Day by Day - french retailer // daybyday-shop.com [Electronic resource] URL: https://daybyday-shop.com/ (date of visit: 03.05.2021)

17. How does the store work, where all the goods are without packaging? // www.thewillage.ru [Electronic resource] URL: https://www.the-village.ru/city/newone/319169-magazin-bez-othodov (date of visit: 03.05.2021)

18. I.D. Kotliarov, Food Processing: Techniques and technology, 51(1), 146-158 (2021) DOI: $10.21603 / 2074-9414-2021-1-146-158$ 
19. S. Gomez y Paloma, L. Riesgo, K. Louhichi, The Role of Smallholder Farms in Food and Nutrition Security (Springer, Cham, 2020)

20. How do retailers care about the environment? // www.dp.ru [Electronic resource] URL: https://www.dp.ru/a/2019/11/25/Retejl_zeleneet (date of vizit: 03.05.2021).

21. S. Bozhuk, N. Kozlova, N. Krasnostavskaya, T. Maslova, IOP Conf. Ser.: Mater. Sci. Eng., 497, 012114 (2019) DOI: 10.1088/1757-899X/497/1/012114

22. I. Kapustina, T. Pereverzeva, T. Stepanova, IOP Conf. Ser.: Mater. Sci. Eng., 497, 012120 (2019) DOI: 10.1088/1757-899X/497/1/012120

23. B12 Zero Waste // vk.com [Electronic resource] URL: https://vk.com/topic169648618_41506619 (date of visit: 03.05.2021)

24. I.D. Kotliarov, Manager, 11 (3), 72-81 (2020) DOI: 10.29141/2218-5003-2020-11-3-6

25. T. Johansson, J. Kask, Journal of Retailing and Consumer Services, 34, 326-333 (2017) DOI: 10.1016/j.jretconser.2016.07.009

26. W. Michalak, L. Calder, Progress in Planning, 60, 111-126 (2003) DOI:10.1016/S0305-9006(02)00094-6

27. G. Wagner, H. Schramm-Klein, S. Steinmann, Journal of Business Research, 107, 257270 (2020) DOI: 10.1016/j.jbusres.2018.10.048

28. G.Yu Mityashin, Upravlenie prodazhami, 2 (109), 128-135 (2021) 